\title{
MANEJO COMUNITÁRIO EM SAÚDE MENTAL E EXPERIÊNCIA DA PESSOA*
}

\section{Carlos Caroso}

\section{Núbia Rodrigues \\ Naomar Almeida-Filho \\ Universidade Federal da Bahia - Brasil}

\begin{abstract}
Resumo: A principal ênfase desse artigo é o papel das instâncias comunitárias no apoio às pessoas que apresentam comportamentos anormais, particularmente a importância da família para a recuperação e reintegração social da pessoa doente. As práticas e ações nas quais os familiares e outros membros da comunidade se engajam são discutidas através da idéia de manejo terapêutico comunitário, entendida como o conjunto de iniciativas de determinadas redes sociais, destinadas a enfrentar as implicações decorrentes de um problema de saúde, o que inclui cuidados diários, busca de tratamento e esforço para sua reabilitação e reintegração social.
\end{abstract}

\begin{abstract}
The importance of community support to people who present problematic behaviors, particularly to the role played by the family as a social support network in the recovery and social reintegration of the sick person, is the main emphasis of this article. Practices and actions on which family and other community members engage are discussed through the idea of community therapeutic management, assumed to constitute a set of initiatives of certain social networks, meant to face the implications resulting from the health problem, among which are daily care, treatment seeking behavior and efforts towards one's social rehabilitation and reintegration.
\end{abstract}

\footnotetext{
A pesquisa "Práticas Familiares e Culturais em Saúde Mental na Bahia" teve apoio do CNPq, Processo 523829/94.9. Este estudo faz parte do programa de pesquisa de uma rede internacional (INECOMInternacional Network for Cultural Epidemiology and Community Mental Health) organizada pelo Dr. Gilíes Bibeau da Université du Montreal, e Dra. Ellen Corin, da McGill University Canadá. Receberam suporte do CNPq os bolsistas Adenilson Silva Fonseca, Cláudia S. Oliveira, Adriana Bastos Silva e Roselene de Alencar Silva. Em pesquisa anterior (Social and Cultural Landmarks in Community Mental Health in Bahia, Brazil - Phase I: Signs, Meanings and Practices in Community Mental Health) participaram da equipe Lélia Lofego Rodrigues, Edna Ferreira Alencar e Samira Bevilaqua. Agradecemos ainda a colaboração de Mônica Lima, bolsista de IC em outro projeto apoiado pelo CNPq, atualmente mestranda no PPGSC/ISC/UFBA.
} 


\section{Introdução}

A discussão sobre o processo de desinstitucionalização do tratamento psiquiátrico nos Estados Unidos da América, iniciada ainda nos anos cinquenta, estimulou vários estudos analisando os papéis da família e da comunidade frente à doença mental, por exemplo: a família como agente causador dos problemas; a família como rede de suporte; a família como agente de reabilitação do paciente; relações entre a família de pacientes psiquiátricos e profissionais de saúde. A importância desses trabalhos está na análise das interações entre as pessoas que apresentam comportamentos problemáticos e seus familiares, no contexto comunitário, isto é, não-psiquiátrico e não-hospitalar. Entretanto, discutem trajetórias de pessoas que, em algum momento de suas histórias, passaram por instituições hospitalares e posteriormente retornaram à vida familiar e comunitária (Fisher; Benson; Tessler, 1990).

No presente artigo, buscamos outra linha de compreensão, tomando a situação de pessoas que apresentam comportamentos problemáticos e que raramente passaram por internações hospitalares, isto é, sujeitos que durante a maior parte de suas vidas receberam cuidados de agentes terapêuticos tradicionais e apoio de redes sociais da própria comunidade em que vivem. Nesse sentido, analisaremos os dados etnográficos de um estudo que conduzimos em um município do litoral norte da Bahia, ${ }^{1}$ com destaque ao papel da comunidade e da família como rede de suporte e rede terapêutica. Objetivamos analisar as experiências diferenciadas que envolvem os familiares e portadores de problemas mentais, bem como os aspectos sociais relacionados.

Nosso interesse não é buscar categorias diagnósticas psiquiátricas, mas identificar o sistema de "signos, significados e práticas” (Corin et. al., 1990) relacionado às experiências individuais, familiares e comunitárias, que serão analisadas a partir de material etnográfico constituído por dois tipos de narrativas: uma centrada na família, para revelar o modo como os envolvidos no grupo familiar percebem a situação; e a outra centrada na reflexão dos próprios sofredores em relação à atenção e cuidados recebidos, bem como sua avaliação particular sobre as interações no âmbito doméstico e com unitário.

1 Questões éticas nos impedem de registrar os nomes dos locais onde conduzimos o estudo, assim como o nome dos informantes cujas entrevistas foram cotejadas no texto. 
Do ponto de vista teórico, este trabalho discute a questão das redes sociais, especificamente voltadas para cuidados terapêuticos.

A idéia de redes comunitárias que adotamos, particularmente as redes de apoio constituídas por familiares, amigos, vizinhos e outros agentes sociais nos cuidados aos portadores de problemas mentais/emocionais, estabelece uma clara diferença entre uma rede e grupo organizado. Neste sentido, concordamos com a concepção de Bott (1976, p. 211), que afirma ser uma rede "uma configuração social onde algumas, mas nem todas, das unidades externas componentes mantêm relações entre si. As unidades externas não constituem um todo social mais amplo. Elas não são cercadas por uma fronteira comum".

A pertinência desta noção está justamente em permitir perceber que as redes de apoio familiar e comunitário, que se formam em torno dos doentes, nem sempre estão claramente articuladas, contudo, operam eficientemente no sentido de prover ao doente os cuidados disponíveis na comunidade. Boissevain (1987) chama atenção para o processo de estruturação e manipulação de redes através do qual os indivíduos se organizam, de diferentes maneiras, para alcançar seus objetivos, dentre eles, conquistar posições sociais, obter ajuda, apoio ou construir alianças; quando estão em situações liminares.

A importância das redes no apoio e tratamento às pessoas que apresentam comportamentos reconhecidos como problemáticos, pode ser dimensionada pela afirmação de Kleinman e Good (1985, p. 502) de que "os significados culturais e as avaliações sociais sobre as desordens apresentadas pelos membros da rede social primária do sofredor, tem uma importante influência tanto na construção da doença como da realidade social, quanto sobre o curso e os seus efeitos sobre a vida do sujeito (doente)".

A despeito de conhecermos os múltiplos significados e definições do conceito de "rede social", por exemplo, "rede egocêntrica delimitada e estrela primária ou estrela de primeira ordem” (Mitchel apud Barnes, 1987), optamos por utilizar a noção de rede total como "uma abstração de primeiro grau da realidade [que] contém a maior parte possível da informação sobre a totalidade da vida social da comunidade à qual corresponde". Neste sentido, Barnes (1987, p. 166) vai mais além ao afirmar que uma "rede social 
é qualquer extração de uma rede total, com base em algum critério que seja aplicável à rede total”.

Nosso propósito neste artigo é apresentar uma abordagem etnográfica e qualitativa das redes sociais de apoio às pessoas que apresentam transtornos emocionais/mentais, para que possamos compreender como essas redes se formam e qual o papel que desempenham no manejo comunitário em saúde mental. Em nosso entendimento, as práticas comunitárias se concretizam nas experiências que marcam a relação cotidiana entre os diferentes interlocutores e a pessoa doente, sendo constituídas por todo e qualquer comportamento de uma rede de apoio familiar e outras redes sociais próximas, que visem a reabilitação e reintegração social das pessoas que apresentam comportamentos considerados problemáticos.

\section{Metodologia}

A pesquisa de campo, cujos dados são parcialmente analisados neste artigo, foi realizada entre os anos de 1994 e 1996, em três localidades com características predominantemente urbana-tradicional e rural, objetivando compreender o manejo comunitário e as práticas e familiares em saúde mental. A problemática foi abordada a partir de uma etnografia do discurso, o que nos levou a centrar a coleta de dados em narrativas pessoais e na realização de uma etnografia focalizada do contexto no qual se verificam as relações sociais que aqui nos referimos.

A estratégia de abordagem etnográfica que desenvolvemos nos possibilitou uma aproximação do discurso sobre a doença mental, das práticas de suporte e dos tratamentos relacionados, seguindo o modelo metodológico do Programa de Pesquisa Social and Cultural Landmarks in Community Mental Health in Bahia, Brazil, ao qual estamos vinculados. Assim, através da análise do texto das entrevistas buscamos identificar: signos (no sentido de comportamentos); gravidade percebida do problema; explicações e interpretações sobre as causas; reações sociais à pessoa afetada; busca terapêutica e a percepção dos impactos do problema e dos tratamentos utilizados (Corin et al., 1990; Almeida-Filho et al., [s.d.]).

As narrativas específicas de informantes-chave, compostas por entrevistas semi-estruturadas, envolvendo agentes terapêuticos do setor 
comunitário; acompanhamentos de casos; história das famílias dos casos e história do caso exploraram as concepções e experiências dos indivíduos com relação às doenças, às causas e tratamentos. As histórias de caso foram particularmente relevantes, uma vez que nos permitiram alterar a relação até então mantida com os denominados casos, trazendo-os à condição de interlocutores de pesquisa. Esta mudança viabilizou a compreensão de sua visão particular sobre a experiência de sofrimento e sobre as várias formas de interação com diferentes grupos de apoio, dentre os quais a família e outras redes sociais próximas.

Complementando as entrevistas semi-estruturadas, realizamos entrevistas não-estruturadas, com o objetivo de intensificar a interação entre pesquisadores e seus interlocutores, abandonando a idéia clássica de informante retida pela Antropologia, bem como expandir a compreensão contextual da vida local, através das múltiplas vozes dos seus narradores.

Ao lado disso, o trabalho de campo fez uso constante da observação participante, que permitiu a "interação face a face" com vários interlocutores em situações e contextos distintos. Privilegiamos visitas frequentes às casas das pessoas que compunham o grupo em estudo. Em várias ocasiões, presenciamos situações sociais e rotinas produtivas, eventos domésticos privados, desentendimentos familiares, cerimônias religiosas, manifestações lúdicas e festas populares, jogos e conversas pelas ruas da cidade, diversas situações de troca, incluindo a ajuda mútua entre iguais, trocas simbólicas e comerciais na feira semanal, que constitui um local privilegiado de sociabilidade, entre outros acontecimentos de grande significação para compreensão do contexto sócio-cultural local. Procedendo desta maneira, através da observação participante conseguimos desvelar as rotinas e dinâmicas dos eventos que elaboram o texto etnográfico da vida cotidiana das pessoas que foram os sujeitos desta pesquisa.

\section{Experiência de portadores de problemas mentais}

Para compreender as experiências pessoais dos portadores de problemas mentais e o apoio comunitário prestado pelas várias instâncias sociais, entre as quais a família e outras redes próximas, inicialmente buscamos examinar a maneira como as concepções culturais sobre os distúrbios mentais influenciam 
a estrutura das respostas dadas pelos doentes e como estas respostas realimentam os modos sociais de conceber as doenças mentais (Greenley, 1990; Eaton et al., 1990).

Na visão de Greenley (1990, p. 4), as concepções culturais sobre doença mental são constituídas pelas "idéias sobre desordens mentais que derivam de categorias conceituais, crenças a respeito do que seja um comportamento certo, bom ou desejável (normas), noções sobre o apropriado e o preferível (valores), e a compreensão incorporada à tecnologia”. O autor reconhece ainda que vários fatores influenciam a maneira como os distúrbios mentais são concebidos e como os doentes são tratados. Entre os quais, ele aponta a disponibilidade de recursos financeiros, interesse profissional, pressões políticas, postura das lideranças carismáticas, a convergência da opinião pública, a introdução de novas tecnologias, a emergência de uma ideologia coerente. Todos estes processos dependem do político, definido como uma ampla gama de conflitos e negociações entre interesses, às vezes, divergentes, que tomam lugar em diferentes arenas - políticas, profissionais, tecnológicas etc. (Greenley, 1990). A partir dessa perspectiva, interessa-nos analisar as relações familiares e comunitárias que se desenvolvem em torno do problema mental, tendo como pano de fundo os processos acima mencionados.

A percepção do comportamento problemático através da ótica dos envolvidos, desvela as experiências de exclusão em diferentes esferas da vida social. Para a família, na maioria das vezes, o doente representa uma "cruz a ser carregada”, pelo "sofrimento” que, em certa medida, pode ser compartilhado com os outros. Para a pessoa com problemas, esta experiência não pode ser compreendida pelos outros do mesmo modo como ela a compreende. Em outras palavras, a pessoa afetada confina-se à sua própria experiência, construída e interpretada de acordo com os modelos que lhe são disponibilizados pelo meio sócio-cultural em que vive. Devemos lembrar que este modelo também é dado pelo tipo de tratamento que recebe, isto é, profissional ou comunitário. Embora cada experiência pessoal seja diversa daquela da família e dos outros membros da comunidade, ela contribui para a redefinição da resposta comunitária à pessoa que se comporta inadequadamente, segundo os padrões comuns ao grupo. Dessa forma, os modelos de resposta e interação são reelaborados, vindo a refletir as tradições culturais e experiências individuais do doente e sua rede de relacionamento. 
Ao longo da experiência de campo e do acompanhamento regular de pessoas que apresentavam comportamentos problemáticos, foi possível observar que embora a vida em comunidade, longe das instituições psiquiátricas, seja fundamental para a reintegração dos que sofrem de problemas mentais (Caroso et. al., 1997), quando se encerram as crises, apresentam-se alguns impedimentos à sua plena ou satisfatória realização.

A maioria dos casos acompanhados, de um total de trinta e dois, é composta por pessoas com menos de trinta e cinco anos de idade. Esta fase é a de maior produtividade para um adulto, sobretudo no que se refere às suas expectativas de sucesso pessoal e social, envolvendo casamento, procriação, conquista de posições no mercado de trabalho e na sociedade. Nas narrativas dos casos que acompanhamos, em sua grande maioria, homens, observamos uma tendência destes interlocutores em compreender seu deslocamento social através de sentimentos de impossibilidade com relação aos aspectos acima apontados.

Para nossos interlocutores, as situações problemáticas remontam à infância, revelando-se no tratamento diferenciado por parte dos pais, muitas vezes acentuado pela violência física e verbal; da comparação com os colegas de classe que tiravam "as melhores notas"; pela exclusão por parte das professoras das atividades coletivas, entre outras formas de segregação social. Na adolescência, descrevem as dificuldades de relacionamento com as garotas, o afastamento dos amigos, a perda de oportunidades de trabalho e migrações mal sucedidas. Estas experiências surgem nos discursos assistematicamente e, em geral, estes eventos não são relacionados ao aparecimento dos comportamentos que, na sua visão, as outras pessoas consideram problemáticos.

Nos momentos de crise, a pessoa que sofre de problemas emocionais vive num mundo só seu, construído de forma diversa e de significados que lhes são exclusivos. Passada a crise, ela experimenta a "ressaca”, os momentos de vergonha e tentativas, às vezes sem sucesso, de retomada da vida normal. Nesse sentido, não se vê como "uma pessoa igual às outras”, imagem que é reforçada por aqueles que a cercam. Contudo, também não se vê como uma pessoa anormal. Aos seus próprios olhos, esta pessoa, perseguida pelo rótulo e estigma que antecipam o comportamento que os outros esperam dela, vê a si mesma como alguém diferente, no mínimo, incompreendida e, por diversas 
razões, estigmatizada, deslocada socialmente, como resultado da ação rotuladora da comunidade.

A trajetória de um dos nossos interlocutores do sexo masculino é ilustrativa, pois revela as tensões familiares em torno de problemas emocionais, a partir de um outro ponto de vista. Trata-se de um homem, atualmente com 33 anos, que não exerce atividades produtivas, embora receba uma aposentadoria por invalidez. Ele vive com a família e divide um quarto com um irmão. Do ponto de vista de sua família, de acordo com o diagnóstico psiquiátrico, este homem é portador de esquizofrenia. Do seu próprio ponto de vista, as pessoas problemáticas são os outros membros de sua família, que passaram a lhe tratar com indiferença, desde que ele retornou à cidade, após uma longa e multivariada experiência de migração por diferentes cidades da Bahia: "eu morei esses anos todos fora, quando cheguei aqui, eles estranharam, eles me tratam como estranho. Agora, quando chega uma pessoa da rua, aí eles tratam como amigo, que é pra dizer que gostam de mim” (J.).

A característica predominante em sua narrativa é a comparação constante com os irmãos, segundo ele, melhores situados na vida e por causa disso, mais valorizados pela família. Além disso, deixa transparecer frustrações e ansiedade em relação ao sexo oposto, quando se compara aos irmãos e amigos mais novos, a outros amigos mais velhos e, em sua opinião, mais feios que já conseguiram se casar ou "se amigar". Por outro lado, a infância representa, para ele, a "idade do ouro" quando todas as pessoas da casa "gostavam" dele e não lhe "abusavam”. Hoje em dia, diferentemente, as tensões familiares, para ele, se revelam em atividades cotidianas, tais como fazer refeições: "quando eu vou comer qualquer coisa, almoçar, eles ficam abusando, reparando o mal feito, contando ao pessoal da rua. Essas coisas que acontece dentro de casa tem que ficar dentro de casa, as pessoas não diz na rua não, porque aqui é um lugar pequeno" (J.).

Os sentimentos de estranheza para com a vida social, e daquilo que consideramos como deslocamento social do portador de problemas psiquiátricos, são acentuados, à medida em que a vida privada em uma comunidade de pequenas dimensões tem maior visibilidade que numa cidade grande, onde os espaços sociais são multivariados, daí o nosso interlocutor reclamar por privacidade. As malhas estreitas das redes sociais em sociedades tradicionais são o resultado de um maior número de relações e maior intensidade desses 
eventos entre as unidades componentes (Bota, op. cit.), levando a vida privada ao domínio público. Assim, a maior ou menor exposição pública parece afetar a percepção do problema por parte da pessoa doente, tal como exemplificado pela reclamação por privacidade na narrativa do nosso interlocutor acima.

Não sendo única, esta é uma das razões para que dos trinta e dois casos que acompanhamos, vinte e quatro sejam do sexo masculino e oito do sexo feminino. Esta diferença numérica não significa que os homens estejam ou sejam mais susceptíveis a transtornos emocionais/mentais que as mulheres, não havendo entre os fatores de causalidade reconhecidos qualquer explicação para o fato. Contudo, tomando a consagrada relação postulada por DaMatta (1991), de que o homem está para a rua (para o espaço público) da mesma forma que a mulher está para a casa (espaço privado), seria equivalente a afirmar que a vida masculina é, em certo sentido mais exposta aos fatores externos ao grupo doméstico, enquanto a vida e experiências sociais das mulheres adaptam-se mais facilmente ao espaço doméstico. Isto pode em parte explicar, o fato de termos encontrado maior referências a pessoas com problemas comportamentais entre o sexo masculino do que do sexo feminino. Conforme os padrões encontrados para o grupo estudado, as expectativas de melhor realização social e públicas são dirigidas aos homens. As frustrações dessas expectativas se tornam igualmente públicas, trazendo graves consequências para a convivência no grupo familiar e vida social na comunidade.

\section{Experiência da família}

Com o objetivo de compreender os signos e significados das práticas envolvidas no manejo comunitário em saúde mental, através das redes sociais comunitárias que se formam em apoio ao doente, tomamos como exemplo um caso de doença mental mencionado por Janzen (1978), cujo contexto de ocorrência assemelha-se ao que nos referimos. Caracterizando a trajetória de reconhecimento da doença, seleção terapêutica e ressocialização de uma mulher que experimentara um surto psicótico, ele destaca que a diferença mais marcante entre os sistemas médicos ocidental e nativo, é a ênfase que o segundo dá ao papel da família e das redes de parentesco no processo de reconhecimento e tratamento das doenças. Ele o opõe ao modelo desenvolvido pela medicina ocidental, segundo o qual a doença é pensada como um fenômeno 
preponderantemente orgânico e, sendo assim tratada, desvincula-se dos condicionantes sócio-estruturais, o que em algumas situações dificulta a reinserção social do doente.

Quando se trata da doença mental, pelo seu caráter estigmatizante, a atuação dos grupos de apoio torna-se mais importante, na medida em que a pessoa mentalmente agravada depende da confiança do seu grupo para que possa reconquistar um espaço social. A despeito das dificuldades e transtornos provocados pelo problema, é da família ou dos grupos sociais próximos o maior esforço para minimizar a situação, seja diante da emergência do problema, seja no trabalho cotidiano que garante a superação de crises e o bem-estar dos envolvidos. Neste caso, é importante pensar que tanto a situação analisada por Janzen quanto as que temos encontrado, dizem respeito a trajetórias de pessoas em idade produtiva e reprodutiva, que passaram por experiências sócio-individuais envolvendo conflitos no relacionamento interpessoal, migração, descumprimento de obrigações morais e religiosas e sobretudo dependência sócio-econômica.

Na análise de Janzen (1978) três elementos aproximam-se fortemente do contexto etnográfico a que nos referimos. Primeiro, a compreensão local da doença mental como um problema muito mais de ordem social que de ordem individual. Segundo, o papel da família como mediadora e fortalecedora de outras redes em torno da pessoa mentalmente afetada, o que ajuda a diminuir o estigma provocado pela doença. Terceiro, a solidariedade difusa que emerge das situações-liminares, envolvendo a desordem emocional/psiquiátrica, que não permite o abandono e total negligência à pessoa doente, apesar do estigma e desagregação social que podem recair, em diferentes níveis, sobre a família. Estes fatos nos levam a investigar como as condições materiais, possibilidades financeiras, nível educacional e inserção religiosa das famílias, influenciam a qualidade e continuidade da assistência e apoio aos seus doentes. Em alguns casos, ao contrário de um problema mental ser considerado a causa da desagregação sócio-individual, ele pode ser entendido como o reflexo de outros fatores que concorrem para tal situação.

Dentre as dificuldades enfrentadas pelas pessoas portadoras de problemas mentais para sua reinserção na vida social, destacam-se o rótulo e o estigma que acompanham a primeira crise. A partir daí, tem-se o início do processo de rotulação da pessoa como "louca", o que representa perda significativa da 
confiança e credibilidade social por parte das outras pessoas. Um dos fatores que exercerão forte influência para que o rótulo e processos decorrentes tenham consequências mais negativas sobre a pessoa, é o tipo de tratamento utilizado para a superação de uma crise, sobretudo através da avaliação social dos resultados.

Quando levadas ao tratamento psiquiátrico, seja ambulatorial ou hospitalar, a pessoa que apresenta comportamentos considerados problemáticos passa a ser rotulada como "louca", sendo o próprio tratamento no setor profissional interpretado como a confirmação desta condição, fato que reforça portanto, o estigma que recai sobre a pessoa. Por outro lado, o tratamento no setor comunitário-religioso, pode resultar na atenuação do estigma, ou mesmo na rotulação positiva da pessoa (esta discussão é aprofundada em Caroso et al., 1997 e Caroso; Rodrigues; Almeida-Filho, [s.d.]).

$\mathrm{Na}$ área que estudamos, as categorias rotuladoras são utilizadas tanto na descrição, quanto na classificação dos comportamentos considerados anormais. Duas delas, "louco" e “doido”, relacionam-se à terminologia médico-psiquiátrica, consequentemente, à necessidade de assistência terapêutica em esfera de igual natureza. Por outro lado, as categorias "possuído", "embruxado", “com encosto”, "mão de morto” e "surra de caboclo" relacionam-se à terminologia do campo religioso afro-brasileiro, resultando no direcionamento dos esforços terapêuticos ao tratamento religioso.

Embora na maioria das vezes aquelas categorias sejam utilizadas para descrever comportamentos semelhantes, a diferença fundamental está no significado contextual de cada uma delas e nos resultados socialmente produzidos. Enquanto o tratamento psiquiátrico reproduz os estigmas associados à loucura, o reconhecimento de que a pessoa está "possuída”, “embruxada”, "com encosto", "mão de morto" ou tomando uma "surra de caboclo", o atenuam ou mesmo negam, transformando em rótulos positivos que mitigam os impactos da crise e contribuem para a recuperação do doente. Ao invés de ser considerada "louca", a pessoa em crise passa a uma daquelas condições, confirmadas pelas medidas terapêuticas religiosas, tais como a "limpeza"² e iniciação no ritual. Neste caso, a categoria "loucura” é tão somente utilizada

2 Identificadas as causas, a "limpeza” ritual é o primeiro passo em qualquer tratamento realizado nos cultos afro-brasileiros predominantes na área. 
como um parâmetro para comparação de comportamentos: "eu estava como 'louca', mas era um ‘encosto' que estava em mim”.

Por outro lado, os aspectos positivos dos tratamentos nas casas de culto afro-brasileiro devem-se, em grande parte, à proximidade entre suas dinâmicas e as dinâmicas familiares, interpretação que novamente nos aproxima dos achados apontados por Janzen (1978). Se considerarmos que no contexto estudado, na maioria das vezes a doença mental não é apontada como a causa da desarmonia familiar, mas como uma consequência desta, fica evidente que este tratamento privilegia a participação da família em diferentes instâncias do processo terapêutico.

De modo diverso ao tratamento psiquiátrico, sobretudo o asilar, os tratamentos no culto afro-brasileiro, em alguns casos, promovem a aproximação ou reaproximação entre a família e o doente, através de um conjunto de prescrições, obrigações rituais e morais que, em muitos casos, envolvem ações solidárias. No tratamento asilar, por outro lado, a participação da família não é possível, uma vez que o internamento significa isolamento, o que impõe severa reelaboração nas relações entre o interno, seus familiares e amigos. As rigorosas escalas de visitas em intervalos de tempo preestabelecidos, restringem drasticamente os contatos do doente com sua realidade anterior aos problemas, o que dificulta, em diferentes graus, sua reinserção neste contexto após a superação da crise. Por outro lado, os familiares de pacientes institucionalizados também se queixam que a falta, ou dificuldade, de diálogo com os profissionais de saúde os impede de discutir e participar das decisões referentes ao tratamento, o que os deixa impotentes enquanto o doente está internado, além de não os preparar para recebê-lo de volta à vida doméstica (Fisher; Benson; Tessler, 1990).

Diversamente do tratamento no setor profissional, nos cuidados familiares às pessoas que sofrem de problemas emocionais/mentais, podemos constatar dois tipos de ação. O primeiro tipo, resumido pela idéia de "tomar conta do doente”, inscreve-se no contexto diário de manutenção, alimentação e observação da pessoa mentalmente perturbada, implicando em cuidados diários com sua higiene, alimentação, segurança e administração de medicamentos, quando prescritos pelo médico, além de afastá-los de situações perigosas e/ou problemáticas. Este empenho no dia a dia, além de ter como objetivo propiciar o bem-estar da pessoa emocional/mentalmente transtornada, faz parte das 
obrigações sócio-morais da família que, não correspondendo às expectativas, poderá sofrer críticas difusas de vizinhos e parentes.

As ações do segundo tipo estão mais relacionadas ao tratamento em agências terapêuticas do setor comunitário, na emergência das crises iniciais e em diferentes situações de agravamento do problema. A busca terapêutica no setor profissional representa cuidado mais específico, envolvendo outros fatores não presentes no dia a dia e exigindo grande mobilização das redes sociais próximas, com o objetivo de decidir não somente o tipo mas, também, o momento adequado para utilização de cada um dos tratamentos.

\section{A experiência social}

Para uma compreensão mais precisa da experiência social dos problemas mentais, é preciso inicialmente avaliar seus impactos sobre a vida da família e outras redes sociais próximas quando seus participantes são privados de bens materiais, bens simbólicos, atividades de lazer, trabalho, entre outras, como consequência da gravidade do estado de um dos seus membros.

Esses impactos sobre a família e as redes sociais próximas podem ser considerados objetivos e subjetivos (Fisher; Benson; Tessler, 1990), destacando-se três tipos: a) econômicos; b) psicossociais; c) emocionais. Vale ressaltar que não podem ser compreendidos isoladamente, uma vez que os problemas gerados pelos “distúrbios” mentais repercutem simultaneamente em várias esferas da vida das pessoas afetadas, dos seus familiares e de outras redes sociais das quais fazem parte.

Os impactos do primeiro tipo, isto é, de ordem económica, são observados tanto com relação ao tratamento, quanto no que se refere à manutenção da família. Para uma família pobre, ou de poucas posses, ter em seu meio uma pessoa com problemas mentais significa, em grande medida, a perda de um colaborador para a manutenção do grupo. Neste caso, deve-se levar em conta que o estigma social dos problemas mentais reduz consideravelmente as oportunidades de trabalho aos portadores.

Além das privações financeiras diretas, tais como salários perdidos ou não ganhos, perde-se ainda a contribuição com o trabalho físico necessário para o cultivo de roças, pesca, construção civil, dentre outras atividades envolvidas na produção, reprodução e manutenção do grupo doméstico, 
considerando que a maioria dos casos estudados está em idade que os habilita participar da população economicamente ativa. Adicionalmente, a família ainda arca os custos, muitas vezes altos, de tratamentos, sobretudo nas crises que demarcam o início do problema, quando se concentram todos os esforços em busca de resolução.

Os impactos aqui denominados de psicossociais podem ser exemplificados pela “vergonha” pública, pelos “vexames”, enfim, pelos constrangimentos que a família passa quando o parente que apresenta comportamento problemático está em crise. Além disso, são impostas outras limitações à vida social, na medida em que durante as crises, os familiares revezam-se nos cuidados, sendo impedidos, muitas vezes de exercer atividades regulares de trabalho, lazer, etc.

Tais limitações, sejam económicas ou psicossociais geram impactos do ponto de vista emocional, na medida em que se instala um mal estar e desarmonia no grupo familiar, em decorrência do comportamento problemático de um dos seus membros. Isto se reproduz em intrigas, trocas de agressão física e verbal entre portadores de problema mental em crise, seus familiares e circunstantes, o que revela uma falta de compreensão a respeito da questão.

Dentre os 32 casos que acompanhamos, foram reconstruídas as histórias de 27 famílias. Nos casos mais crónicos e mais antigos, a memória do grupo com relação ao surgimento do problema foi se apagando com o tempo. Os familiares perderam um pouco a noção do que foi a doença em seu princípio, devido à longa convivência com as sucessivas e diferenciadas crises do doente. Com o passar do tempo, principalmente para as famílias mais pobres, esta perda da memória emocional, com relação aos aspectos negativos da doença, foi sendo substituída pela lembrança das dificuldades financeiras, sobretudo pela dependência do doente na família.

Segundo o padrão de "normalidade” socialmente esperada, ao atingir a idade adulta, uma pessoa deve criar sua própria unidade doméstica ou contribuir financeiramente para as despesas, quando permanece no domicílio de origem. Quando se trata das mulheres, há expectativas de auxílio no trabalho doméstico, como uma marca do desempenho completo do papel feminino. Com relação à pessoa emocionalmente transtornada, estas expectativas são parcial ou totalmente frustradas pela sua incapacidade em participar plenamente de atividades produtivas ou socialmente relevantes. 
A medida em que o doente se torna mais velho e o problema se cronifica, ele ocupa o lugar das gerações mais novas, que não raro, compõem o grupo doméstico (tais como netos, sobrinhos, enteados, filhos de criação). Nestes casos, a grande dificuldade da pessoa com um transtorno mental/emocional é desempenhar plenamente seu papel de adulto, dado pela idade e aparência, uma vez que ocupa posição semelhante ou, às vezes inferior, à das crianças e idosos que não participam diretamente de atividades econômicas. Vale lembrar que os idosos muitas vezes contribuem financeiramente com os recursos de pensões e aposentadorias e em alguns casos são os donos dos imóveis ocupados pelo grupo doméstico, além de caber às mulheres mais velhas a responsabilidade de "zelar" pela casa, crianças e unidade da família. Algumas crianças contribuem com pequenos serviços, às vezes remunerados, sobretudo durante o verão quando aumenta a demanda por mão-de-obra para atendimento ao turismo, nas localidades costeiras estudadas.

Esta dificuldade pode ser minimizada quando o doente obtém pensão por invalidez, o que acaba se tornando não apenas um alívio para a família, como uma fonte de renda monetária segura e constante. Contudo, em algumas situações, esta é a principal fonte de conflito, quando o doente/pensionista utiliza o recurso recebido em seu exclusivo benefício e, além disso, tem moradia e alimentação às expensas da família.

Entre as iniciativas que poderíamos destacar como parte importante no manejo terapêutico familiar estão as tentativas de encontrar trabalho para a pessoa com comportamento problemático e, desse modo, melhorar sua situação fora e dentro do grupo doméstico. O trabalho passa a ter um fim não somente econômico, mas sobretudo terapêutico e social.

Para ilustrar o último ponto discutido, tomamos o caso de um homem jovem residente com a família, em uma das localidades costeiras. A família pertence à "elite" local de pequenos proprietários de terras e comerciantes no ramo de alimentos, além de ter envolvimentos com a política partidária. Ele concluiu o segundo grau escolar e tentou tornar-se jogador de futebol profissional, entretanto, não alcançou seu objetivo pessoal. O grupo doméstico é composto pela mãe, uma filha, dois filhos (incluindo ele próprio) e um filho de "criação". O pai abandonou a casa quando o comportamento problemático do filho se agravou.

Periodicamente ele apresenta crises depressivas, seguidas por consumo excessivo de bebidas alcoólicas, maconha, além de violência verbal. Por duas 
vezes foi internado por curtos períodos em instituições psiquiátricas, em Salvador, fatos que o marcaram profundamente. Em outra crise, ele foi levado a urna casa de culto afro-brasileiro, na própria localidade, para ser submetido a tratamento. Ficou em reclusão no quarto ${ }^{3}$ por sete dias, ao fim do qual apresentou sensível melhora no comportamento e na relação com as pessoas da família e da comunidade.

Entretanto, sem emprego à época, ele migrou para o Rio de Janeiro, com o objetivo declarado de se casar com uma prima. Após três meses, retornou à sua terra natal, pois as alternativas profissionais disponíveis não lhes satisfizeram. As disputas com o irmão, bem colocado profissionalmente como professor e ocupante de um cargo de confiança na administração do município, agravaram as tensões familiares previamente existentes. Através de arranjos políticos, a mãe conseguiu arrumar uma colocação para ele na prefeitura municipal. A partir destes acontecimentos, aliados ao tratamento que ele passou a seguir rigorosamente estimulado pela nova condição sócio-profissional, a situação doméstica melhorou e as crises depressivas ficaram mais espaçadas.

Contudo, o novo prefeito do município decidiu realizar um concurso público para todos os níveis, incluindo os cargos de confiança (posto que nosso interlocutor ocupava na secretaria municipal de obras). Sob fatores estressantes, o tratamento foi negligenciado, provocando transtornos domésticos. A família temia que ele não conseguisse participar do concurso e ficasse novamente sem emprego, o que poderia agravar seu problema. Com o apoio de diferentes redes, conseguiu a desejada aprovação e manutenção do emprego, resultando em normalização da situação e aumento das expectativas da família quanto à sua total recuperação.

O relativo sucesso deste caso se deve em grande medida, ao equilíbrio financeiro, emocional e sobretudo social da família. Quando comparamos com outros casos, que fazem parte de grupos domésticos de menores posses, percebemos a fragilidade das redes de apoio externas à família. No caso deste homem jovem, a mãe e o irmão mobilizaram outras redes, isto é, os parentes e amigos ligados à política local, para conseguir sua aprovação, uma vez que a grande maioria dos concorrentes foi reprovada e sua própria contagem de pontos não indicava que ele fosse bem sucedido.

3 O quarto (camarinha) é o local onde são "recolhidas" as pessoas a serem iniciadas e/ou tratadas nas casas de culto afro-brasileiro locais. 
Para aqueles pertencentes às camadas mais baixas, as oportunidades são mais reduzidas. Tomamos, a título de exemplo e comparação, o caso de um outro homem da mesma faixa etária, também residente na área costeira. $\mathrm{O}$ grupo doméstico ao qual pertence é composto por sua mãe, sua avó, ele e mais cinco irmãos de diferentes idades, ocupando uma casa de cinco cômodos. A renda familiar não ultrapassa um salário mínimo de aposentadoria da avó, somado aos ganhos irregulares da mãe, como prestadora de serviços domésticos, tais como lavagem de roupa e faxina, e de duas irmãs mais velhas, que desempenham ocasionalmente a função de “ajudantes de cozinha” em um dos restaurantes da localidade, o que está diretamente subordinado ao fluxo de turistas e visitantes.

O homem em causa não exerce atividades produtivas, estudou até a quinta série do primeiro grau escolar e nunca foi submetido a tratamento médico profissional. Ele descreve-se como alguém socialmente deslocado e se considera "melhor do que o povo" do local. Devido a sua baixa escolaridade, não consegue arranjar o tipo de emprego que julga adequado para si. Também não se satisfaz com as poucas oportunidades disponíveis, tais como pescador, ajudante de pedreiro, caseiro, comerciante, vendedor na feira etc.

Os frequentes conflitos domésticos envolvem a disputa pelos escassos bens materiais que a família dispõe e o comportamento moral e sexual do caso, julgado inadequado. São constantes as reclamações pela prática pública da masturbação e atentado sexual contra as irmãs. Por outro lado, sua megalomania é motivo de gracejos na comunidade, situação que o deixa profundamente irritado e insatisfeito com a vida que leva. É importante observar que a despeito dos problemas causados pelo comportamento deste membro do grupo doméstico, nenhum tratamento foi buscado para o caso entre os recursos das agências formais ou comunitárias. Considerando-se os parcos recursos do grupo familiar, o apoio de moradia e alimentação representem muito, sendo o principal papel de sua família dar-lhe suporte informal.

\section{Comentários finais}

No presente, as redes de apoio comunitário às pessoas que apresentam problemas mentais enfrentam as crescentes pressões externas de fatores emergentes no cenário local, o que poderá resultar em substanciais alterações nas 
atuais práticas a médio e longo prazo. A nova economia de mercado que vem se implantando em toda a área, respondendo à acentuada demanda turística nos últimos anos, contribui para a substituição das formas tradicionais de obtenção de alimentos, tais como a pesca e a agricultura de pequena escala, o que torna mais difícil a manutenção de pessoas adultas que não contribuem economicamente para as despesas domésticas, sendo o caso de várias das famílias que estudamos. ${ }^{4}$

Contudo, mesmo frente ao processo de mudança, as estruturas comunitárias continuam a atuar para a resolução deste tipo de problema. Do ponto de vista moral, uma família que abandona um parente incapacitado de colaborar financeiramente, seja por problemas físicos ou mentais, está sujeita a sofrer críticas difusas por parte do grupo, passando a ser socialmente mal vista.

O principal papel das redes comunitárias, particularmente da família, nessas situações, é prover o apoio necessário para que a pessoa mentalmente perturbada possa ultrapassar as fases mais difíceis, enfrentar a rotulação, o estigma e diferentes tipos de pressões sociais. É nesse sentido que se configuram as ações que denominamos de manejo comunitário em saúde mental, incluindo as práticas familiares. Em outras palavras, o manejo corresponde ao conjunto de ações dirigidas à preservação da integridade do doente e busca de recuperação da sua saúde. Incluem-se os esforços terapêuticos domésticos, a busca e seleção terapêutica subsequente, o encaminhamento às instâncias de tratamento julgadas adequadas, ${ }^{5}$ a contribuição com os gastos financeiros com os tratamentos, o apoio continuado e, sobretudo, a esperança de que a pessoa afetada se recupere e possa desempenhar os papéis que lhe estão reservados na família e na sociedade.

Em um sentido estrito, a maioria dos casos que acompanhamos, segundo padrões que poderiam ser aplicados pela psiquiatria, pode ser caracterizada pela cronicidade da doença. Em consequência da diminuição ou perda total das esperanças de restabelecimento ou melhora do paciente, a busca terapêutica se reduz com o decorrer do tempo, passando o doente apenas a receber cuidados mínimos e manutenção diária. Entretanto, uma das nossas intenções é demonstrar que a simples preocupação em prover alimentos diários, abrigo

\footnotetext{
4 Sobre os efeitos da atividade turística nas formas de produção tradicionais, ver Caroso e Rodrigues (1998) e Woortmann (1992).

5 Sobre os fatores envolvidos na decisão terapêutica, ver Young (1981).
} 
e segurança aos doentes, por exemplo, controlando seus passos para que não fiquem expostos nas ruas ou à curiosidade pública, é de grande importância para se compreender o papel das redes terapêuticas formadas em resposta à doença, e a maneira como são utilizados dos recursos comunitários em saúde.

Para fortalecer nosso argumento sobre a eficácia do manejo comunitário em saúde mental, é significativo destacar que, nas localidades onde esta pesquisa foi conduzida são raros os "loucos de rua", no sentido de desabrigados que perambulam pela cidade, apesar da presença de muitos doentes crônicos, com poucas possibilidades de recuperação, que potencialmente poderiam estar nesta categoria. Apenas um homem, desmemoriado e mentalmente perturbado, de procedência desconhecida, que chegou a uma das localidades há mais ou menos vinte anos, vive nessa condição. Mesmo não tendo família ou residência fixa, este "louco de rua" está envolvido e tem proteção das redes comunitárias, contando com apoio e cuidados espontâneos de várias pessoas, que lhe provêem alimentos, cuidam da sua higiene e lhe dão abrigo noturno. Apesar das suas peculiaridades, e.g., não ser do local, não ter referenciais identitários nem família, esta pessoa é amparada pelas redes de apoio comunitário, instâncias de suporte em saúde mental.

\section{Referências}

ALMEIDA-FILHO, N. et al. Signos, significados e práticas em saúde mental: desafio metodológico e experiência de campo. In: PITTA, A. (Org.). Cultura \& saúde mental. São Paulo, [s.d.]. No prelo.

BARNES, J. A. Redes sociais e processos políticos. In: FELDMAN-BIANCO, B. (Org.). Antropologia das sociedades contemporâneas. São Paulo: Global Universitária, 1987. p. 159-194.

BOISSEVAIN, J. Amigos de amigos: redes sociais, manipuladores e colisões. In: FELDMAN-BIANCO, B. (Org.). Antropologia das sociedades contemporâneas. São Paulo: Global Universitária, 1987. p. 195-223.

BOTT, E. Família e rede social. Rio de Janeiro: Francisco Alves, 1976. 
CAROSO, C.; RODRIGUES, N. Nativos, veranistas e turistas: identidades, mudança e deslocamento sócio-cultural no litoral norte da Bahia. Revista Turismo em Análise, São Paulo: ECA/USP, v. 9, n. 1, jul. 1998.

CAROSO, C.; RODRIGUES, N.; ALMEIDA-FILHO, N. Rótulo, estigma e transtornos mentais: um estudo etnográfico na Bahia. In: PITTA, A. (Org.). Cultura \& saúde mental. São Paulo, [s.d.]. No prelo.

CAROSO, C. et al. When healing is prevention: Afro-Brazilian religious practices related to mental disorders and associated stigma in Bahia, Brazil. Curare, Berlin: WWB, v. 12, p. 195-214, 1997.

CORIN, E. et al. Comprendre pour soigner autrement: reperes pour regionaliser les services de santé mentale. Montréal: Les Presses de l’Úniversité de Montréal, 1990.

DAMATTA, R. A casa e a rua. Rio de Janeiro: Guanabara-Koogan, 1991.

EATON, W. W. et al. Psychiatric epidemiology and psychiatric sociology: influences on the recognition of bizarre behaviors as social problems. In: GREENLEY, J. R. (Ed.). Research in community and mental health: mental disorder in social context. London: Jai Press, 1990. v. 6.

FISHER, G. A.; BENSON, P. R.; TESSLER, R. C. Family response to mental illness; development since deinstitutionalization. In: GREENLEY, J. R. (Ed.). Research in community and mental health: mental disorder in social context. London: Jai Press, 1990. v. 6.

GREENLEY, J. R. (Ed.). Research in community and mental health: mental disorder in social context. London: Jai Press, 1990. v. 6.

JANZEN, J. M. The quest for therapy in Lower Zaire. Berkeley: University of California Press, 1978.

KLEINMAN, A.; GOOD, B. Culture and depression. Berkeley: University of California Press, 1985. 
WOORTMANN, E. F. O ambiente e a mulher: o caso do litoral do Rio Grande do Norte, Brasil. Latin American Studies, n. 12, 1992.

YOUNG, J. C. Medical choice in a Mexican village. New Jersey: Rutgers, 1981. 